\title{
Predictors of mortality in emergency department patients with chest pain without cardiovascular emergencies
}

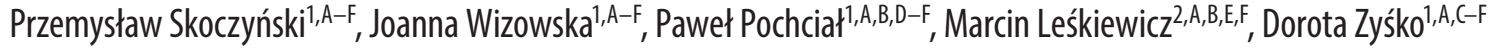 \\ ${ }^{1}$ Department and Clinic of Emergency Medicine, Wroclaw Medical University, Poland \\ 2 Department of Medical Emergency, Wroclaw Medical University, Poland \\ A - research concept and design; $\mathrm{B}$ - collection and/or assembly of data; $\mathrm{C}$ - data analysis and interpretation; \\ $D$ - writing the article; $E$ - critical revision of the article; $F$ - final approval of the article
}

\section{Address for correspondence \\ Dorota Zyśko \\ E-mail: dzysko@wp.pl \\ Funding sources \\ The presented test results realized within the subject according to the records in the Simple system, \\ NNo. STA 280.16.0, were financed by the Minister of Science and Higher Education.}

\section{Conflict of interest \\ None declared}

Received on 0ctober 15, 2018

Reviewed on November 14, 2018

Accepted on June 27, 2019

Published online on January 30, 2020

\section{Cite as}

Skoczyński P, Wizowska J, Pochciał P, Leśkiewicz M, Zyśko D. Predictors of mortality in emergency department patients with chest pain without cardiovascular emergencies. Adv Clin Exp Med. 2020;29(1):147-155. doi:10.17219/acem/110325

DOI

10.17219/acem/110325

\section{Copyright}

Copyright by Author(s)

This is an article distributed under the terms of the

Creative Commons Attribution 3.0 Unported (CC BY 3.0)

(https://creativecommons.org/licenses/by/3.0/)

\begin{abstract}
Background. Chest pain is one of the most frequent symptoms in patients seeking treatment at emergency departments (ED). These patients differ according to the cause of their reported symptoms and resultant mortality.

Objectives. Evaluation of the influence of hospitalization and biochemical parameters on mortality rates in patients admitted to the ED with chest pain, in whom no cardiovascular emergencies were established.

Material and methods. The study group consisted of 243 patients with chest pain admitted to the ED in the Wroclaw Medical University Clinical Hospital, Poland, between January 1 and March 31, 2015, in whom no specific diagnosis was made at discharge. A retrospective analysis was carried out based on medical documentation, and 60-day and 1-year survival was assessed.

Results. In the study group, the 60-day mortality rate was $0.8 \%$ (2 persons) while the 1-year mortality rate was $6.6 \%$ (16 persons). The stepwise multivariable logistic regression analysis revealed that 1-year mortality was related to increased level of D-dimer (odds ratio $(\mathrm{OR})=8.5,95 \%$ confidence interval $(95 \% \mathrm{Cl})=21.9-37.5$, $p<0.005)$, age (OR (per year) $=1.10,95 \%(\mathrm{Cl}=1.03-1.18, \mathrm{p}<0.03)$ and lower than $12 \mathrm{~g} / \mathrm{dL}$ hemoglobin concentration (OR $=18.5,95 \% \mathrm{Cl}=4.2-80.4, \mathrm{p}<0.001)$. Troponin I (TNI) levels and hospitalization were not related independently to mortality when other clinical factors were considered.

Conclusions. Hospitalization of patients with chest pain who were not diagnosed with cardiac emergencies is not related with better survival than of those discharged home from the ED. The 60-day mortality is very low and occurs in older patients with numerous comorbidities. In multivariate analysis, survival of the 1-year period depends on the patient's age, hemoglobin levels and D-dimer levels. Risk of death in patients admitted to the ED due to chest pain in whom the cause of the chest pain was not due to cardiovascular emergencies depends on the presence of old age and comorbidities.
\end{abstract}

Key words: hospitalization, emergency department, D-dimer, chest pain, troponin I 


\section{Introduction}

Chest pain is one of the most frequent symptoms in patients seeking treatment at the emergency department (ED). These patients form a heterogeneous group. They differ regarding the cause of reported symptoms and resultant mortality. Diagnosis in the ED should make it possible to quickly determine patients at highest risk, requiring a rapid introduction of treatment and longer hospitalization. Chest pain can result from coronary artery disease (CAD), pulmonary embolism (PE) and acute aortic syndrome (AAS) as well as non-cardiac causes. A key role in diagnosing acute coronary syndrome (ACS) is played by diagnostic algorithms based on electrocardiography (ECG) testing and troponin concentration as well as D-dimer and imaging studies in the cases of suspected PE or AAS. ${ }^{1-5}$ Patients with the same pathomechanism of pain may vary greatly with regard to the risk of death.

Patients who present with ACS also form a heterogeneous group. The risk of death among patients with myocardial infarction with a persistent ST segment elevation (STEMI) is significantly higher than among patients with myocardial infarction without a persistent ST segment elevation (NSTEMI). These differences become less significant over longer observation. After 2 years, the mortality rate between these groups does not differ significantly, which most likely results from the differences in age and comorbidities in both groups. Patients with NSTEMI tend to be older and with more comorbidities than patients with STEMI.

Patients who present with unstable angina (UA) are characterized by the lowest mortality rate ${ }^{6-8}$; however, a lack of increased concentration of myocardial injury markers in this group may be a cause for underestimation of the risk of death, especially in patients with an atypical presentation of the disease. The differences in the risk of death lead to different diagnostic and therapeutic strategies. It is doubtless that patients with STEMI should undergo revascularization as quickly as possible. The guidelines for patients with NSTEMI and UA are likewise clear. Patients who cannot be qualified into any of these groups even after chest pain diagnostic algorithms have been followed, pose particular difficulties. This relates to patients with stable angina whose risk of death is significantly lower compared to patients with ACS, but significantly greater compared to patients with non-cardiac causes of chest pain such as intercostal neuralgia, degenerative spinal changes or dyspeptic symptoms. The introduction of highly sensitive methods of troponin level marking has significantly quickened the diagnosis of ACS but at the same time reduced its accuracy.

Difficulties also arise in patients whose troponin levels are only negligibly increased and remain stable in subsequent tests. The abovementioned biochemical picture in addition to an atypical angina history are not characteristic for ACS; however, they indicate a chronic heart injury and are associated with a worse long-term prognosis. ${ }^{9-13}$ An atypical course of the disease as well as difficulties in identifying unequivocal symptoms reported by a patient pose additional diagnostic challenges, often leading to an underestimation of the risk of death among these patients. In the population of patients diagnosed in the ED, there is a large group of patients in whom ACS as well as other conditions posing an immediate threat to the patient's life have been excluded but no definitive cause of their symptoms has been established. In such cases, an outpatient follow-up is typically recommended. Taking into consideration the significant differences in these patients' characteristics, i.e., CAD diagnosed prior to admission or a lack thereof, or the presence of atherosclerosis risk factors or other comorbidities, the diagnostic strategy should be more personalized and clearly outlined.

Difficulties in accessing outpatient specialist care constitute an additional obstacle and may lead to delays in proper identification of patients with a greater risk of death, who would benefit from rapid diagnosis. Patients with chest pain, who despite an initial exclusion of cardiogenic causes of that chest pain in the ED are qualified for admission to different departments for further diagnosis and treatment, form a separate group. This usually concerns patients with a higher cardiovascular risk and more comorbidities. It is not clear, however, that patients benefit, especially when a longer hospitalization does not lead to verification of the initial diagnosis and qualification to invasive diagnostics of CAD and revascularization of the heart muscle.

\section{Objectives}

The objective of this study was to evaluate the influence of hospitalization on mortality rates in patients admitted to the ED with chest pain, in whom no serious cause of pain like ACS, PE, AAS, or decompensated congestive heart failure (CHF) was established either prior to discharge from the ED or in the department they were referred to from the ED.

The second objective of this study was to determine the significance of biochemical parameters tested in the ED as predictive factors in the total 60-day and 1-year mortality.

\section{Material and methods}

The parameters presented herein were assessed in 283 patients, in whom 2 measurements of troponin I (TNI) were taken during their hospitalization and in whom no myocardial infarction was diagnosed, and no non-cardiac causes of chest pain were definitively diagnosed. The group consisted of 123 male patients aged $61.2 \pm 16.0$ years and 160 female patients aged $71.9 \pm 13.8$ years. Data on the status of 272 of the patients (deceased or living) was obtained 
from the Polish Ministry of Digital Affairs. Owing to the discrepancies in this data pertaining patient's name or surname, 11 patients were eventually disqualified from the study. Out of this group, 186 patients were discharged home and 86 patients were admitted to other departments of the hospital.

The patients admitted to other hospital departments were diagnosed with cardiovascular emergency (29 patients) or cardiovascular emegency was excluded (57 patients). However, they were admitted for further evaluation and treatment. Cardiovascular emergency was defined as ACS, decompensated CHF or PE.

Finally, the group studied consisted of 243 patients. The flow diagram of the study is presented in Fig. 1. A retrospective analysis was carried out based on an analysis of the following metrics from the medical documentation: age, gender, presence of comorbidities such as CAD, hypertension, diabetes, past stroke, TNI levels at admission (TNI1) and after $3 \mathrm{~h}$ (TNI2), sodium levels, potassium and glucose levels, as well as D-dimer levels if available. A 12-lead ECG was analyzed with a 7-step interpretation algorithm. Baseline rhythm, electric axis, conduction disorders, enlargement and hypertrophy of the heart cavities, ischemia, and arrhythmias were assessed. None of patients had a implanted pacemaker. ${ }^{14}$ Ischemia was found if $\mathrm{T}$ wave inversion was present in leads other than $\mathrm{VVR}, \mathrm{V} 1$ or III, or when ST segment depression was present. The final diagnosis of the hospitalized patients was assessed on the basis of discharge diagnoses. After establishing a database, the life status of the patients was determined based on data from the Polish Ministry of Digital Affairs.

\section{Statistical analysis}

Continuous variables were presented as means and standard deviations (SD) while discrete variables were presented as numbers and percentages. The continuous variables were analyzed as raw data as well as after dichotomization, taking into account the values of the reference range.

Age was analyzed as a continuous variable and the cut-off point resulted from receiver operating characteristic (ROC) curves. Troponin I values were analyzed as a continuous variable, as well as normal or elevated values throughout the duration of the study. The norm of TNI level established was $0-0.029 \mathrm{ng} / \mathrm{mL}$. D-dimer levels were analyzed as a continuous variable as well as normal or elevated values, with the normal values accepted as $0.5+$ age $<50 / 100$. Hemoglobin levels were analyzed as a continuous variable and after dichotomization, on the basis of ROC curve analysis results.

Comparisons of the variables were made using the Student's t-test, the Mann-Whitney U test and the $\chi^{2}$ test depending on the distribution of the variables where $\mathrm{p}<0.05$ was considered statistically significant. The 60-day and 1-year survivals were assessed as numbers and percentages. The ROC curves were constructed and area under the curve (AUC) was constructed to find cut-off points for the age and biochemical parameters which differed between survivors and non-survivors. The AUC and p-values were evaluated. If AUC was 1, the cut-off point was perfect, if $>0.8$ it was good, if $0.6-0.8$ it was moderate, and if $<0.6$ it was poor. The determined cut-off points were regarded as significant where AUC was at least 0.6 and the p-value was less than 0.05. A multivariable analysis was performed taking significant biochemical and clinical parameters as dependent variables which varied depending on the group, with $\mathrm{p}<0.15$.

To assess the presence of multicollinearity, the Spearman's rank coefficients were calculated. The multivariable analysis was carried out using the stepwise multivariate logistic regression analysis as well as the Classification and Regression Trees (CART) analysis. The results of stepwise multivariable logistic regression analysis were presented as odds ratios (OR) and 95\% confidence intervals (95\% CI). The CART analysis divides a large heterogeneous population into smaller, more homogeneous populations which

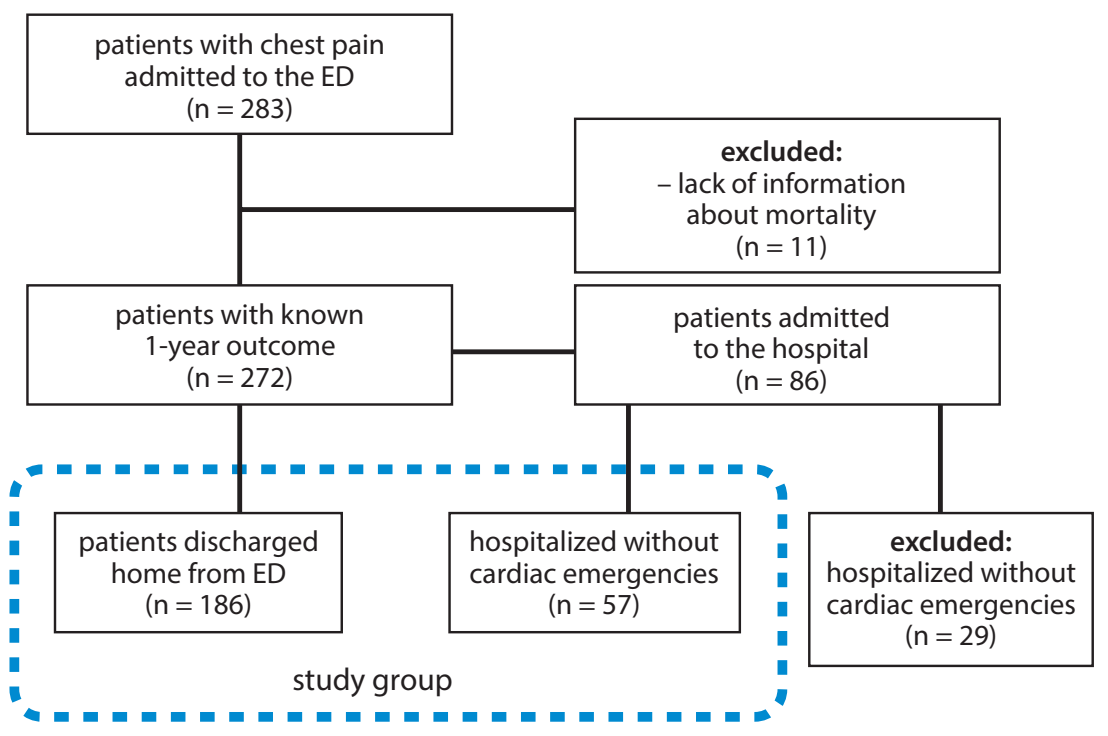

Fig. 1. Flow diagram of the study. The study group consists of 243 patients, 186 patients discharged home from the ED and 57 patients hospitalized without cardiovascular emergencies (ACS, PE, significant coronary stenosis, decompensated CHF, AAS). The boxes of patients qualified and included in the study group are circled with a dashed line 
may differ in term of outcomes, e.g., mortality, as in our study. The number in the upper right corner depicts whether in the given subgroup the mortality rate is lower than in the total population (0) or is higher than in the total population (1).

The accuracy of a global 10-fold cost validation (CV) was presented as global cost and its SD. The age was correlated with other variables (Spearman's rank correlation coefficient up to 0.40 ) - therefore, 2 models were built, with and without age. The p-value less than 0.05 was considered statistically significant.

\section{Results}

The study group consisted of 243 patients aged $66.3 \pm 16.0$ years: 139 women aged $71.2 \pm 14.1$ years and 104 males aged $59.8 \pm 16.2$ years. A total of 57 (23.5\%) patients were hospitalized further and 186 (76.5\%) patients were discharged home from ED.

In Table 1, demographic and clinical characteristics as well as biochemical test results are presented for both groups of patients: those who were hospitalized without cardiovascular emergencies and those discharged home.

Hospitalized patients were older, had higher rates of diabetes or past stroke, were more likely to be diagnosed with CAD, as well as presented with higher levels of TNI at admission and after $3 \mathrm{~h}$, higher levels of D-dimers, lower levels of hemoglobin, and higher levels of C-reactive protein (CRP) and creatinine. In the study group, the 60-day mortality rate was $0.8 \%$ ( 2 persons) while the 1 -year mortality rate was $6.6 \%$ (16 persons). Of the 2 persons who died within 60 days of admission to the ED, 1 patient was hospitalized in another department and 1 patient was discharged home. The mean age of the 2 patients who died was 86 years. Of the 16 persons who died within 1 year after admission to the ED, 8 patients (50\%) were hospitalized without recognized cardiovascular emergencies and 8 patients (50\%) were discharged home from the ED (Table 2).

Because the 60-day mortality was very low, no further statistical analysis was performed. The 1-year survivors were younger, had lower TNI levels at admission and after $3 \mathrm{~h}$, lower D-dimer and potassium levels, and higher sodium and hemoglobin concentrations (Table 3).

Table 1. Demographic and clinical characteristics and biochemical test results of patients hospitalized without serious diagnosis and patients discharged home

\begin{tabular}{|c|c|c|c|}
\hline Characteristics* & $\begin{array}{l}\text { Hospitalized without cardiovascular } \\
\text { emergencies diagnosis } \\
\qquad(n=57)\end{array}$ & $\begin{array}{l}\text { Discharged home from ED } \\
\qquad(\mathrm{n}=186)\end{array}$ & $p$-value \\
\hline Male gender, n (\%) & 19 (33.3) & $85(45.7)$ & 0.10 \\
\hline Age [years] & $73.2 \pm 13.1$ & $64.2 \pm 16.3$ & 0.002 \\
\hline Hypertension, n (\%) & $42(73.7)$ & $107(57.5)$ & 0.07 \\
\hline Diabetes, n (\%) & $17(29.8)$ & $24(12.9)$ & 0.003 \\
\hline Coronary artery disease, $n(\%)(n=240)$ & $29(53.7)$ & $59(31.7)$ & 0.003 \\
\hline Past stroke, n (\%) & $8(14.4)$ & $12(6.5)$ & 0.09 \\
\hline Systolic blood pressure [mm Hg] & $139.2 \pm 21.2$ & $136.4 \pm 20.5$ & 0.36 \\
\hline $\mathrm{HR}[\mathrm{bpm}]$ & $79.1 \pm 15.8$ & $77.9 \pm 14.3$ & 0.58 \\
\hline TNI at admission [ng/mL] & $0.30 \pm 0.36$ & $0.01 \pm 0.03$ & $<0.001$ \\
\hline TNI at admission above normal levels, n (\%) & $17(29.8)$ & $12(6.5)$ & $<0.001$ \\
\hline TNl after $3 \mathrm{~h}[\mathrm{ng} / \mathrm{mL}]$ & $0.49 \pm 1.6$ & $0.02 \pm 0.08$ & $<0.001$ \\
\hline TNI after 3 h above normal levels, n (\%) & $31(54.4)$ & $21(11.3)$ & $<0.001$ \\
\hline TNI after $3 \mathrm{~h}$ higher than at admission, $\mathrm{n}(\%)$ & $28(49.1)$ & $26(14.0)$ & $<0.001$ \\
\hline Hemoglobin [g/dL] & $13.1 \pm 2.4$ & $13.8 \pm 1.7$ & 0.006 \\
\hline Sodium $[\mathrm{mEq} / \mathrm{L}]$ & $138.5 \pm 4.4$ & $138.7 \pm 3.9$ & 0.85 \\
\hline Potassium $[\mathrm{mEq} / \mathrm{L}]$ & $3.8 \pm 0.5$ & $4.0 \pm 0.6$ & 0.16 \\
\hline Glucose [mg\%] $(n=229)$ & $152.1 \pm 52.6$ & $123.5 \pm 36.3$ & $<0.001$ \\
\hline Creatinine [mg\%] & $1.03 \pm 0.28$ & $1.00 \pm 0.62$ & 0.68 \\
\hline D-dimer $[\mu \mathrm{g} / \mathrm{mL}](\mathrm{n}=215)$ & $1.35 \pm 1.58$ & $0.58 \pm 0.61$ & $<0.001$ \\
\hline D-dimer above normal levels, $n(\%)(n=215)$ & $24(48.0)$ & $40(24.2)$ & $<0.001$ \\
\hline CRP $[\mathrm{mg} \%](\mathrm{n}=226)$ & $9.6 \pm 12.9$ & $7.2 \pm 17.7$ & 0.33 \\
\hline Magnesium [mg\%] (n = 188) & $1.91 \pm 0.36$ & $1.98 \pm 0.23$ & 0.12 \\
\hline ECG results normal, n (\%) & $26(45.6)$ & $38(20.4)$ & $<0.001$ \\
\hline
\end{tabular}

* In cases where no results for a specific patient were available, the $n$ value for persons whose results were available was used. ED - emergency department; HR - heart rate; TNI - troponin I; CRP - C-reactive protein; ECG - electrocardiography. 
Table 2. Comparison of clinical and biochemical parameters of patients who survived 60 days as well as patients who died within this timeframe

\begin{tabular}{|c|c|c|c|}
\hline Characteristics* & $\begin{array}{l}\text { Patients who died within } 60 \text { days } \\
\qquad(\mathrm{n}=2)\end{array}$ & $\begin{array}{l}\text { Patients who survived } 60+\text { days } \\
\qquad(n=241)\end{array}$ & $p$-value \\
\hline Male gender, n (\%) & $0(0)$ & $104(43)$ & 0.22 \\
\hline Age [years] & $86(14)$ & $66(16)$ & 0.08 \\
\hline Hypertension, n (\%) & $2(100)$ & $147(61)$ & 0.26 \\
\hline Diabetes, n (\%) & $2(100)$ & $39(16)$ & 0.001 \\
\hline Coronary artery disease, $n(\%)(n=240)$ & $1(50)$ & $87(37)$ & 0.69 \\
\hline Past stroke, n (\%) & $0(0)$ & $20(8.3)$ & 0.67 \\
\hline Systolic blood pressure [mm Hg] & $156 \pm 27$ & $137 \pm 21$ & 0.19 \\
\hline $\mathrm{HR}[\mathrm{bpm}]$ & $87 \pm 5$ & $78 \pm 15$ & 0.42 \\
\hline TNI at admission [ng/mL] & $0.02 \pm 0.03$ & $0.06 \pm 0.55$ & 0.90 \\
\hline TNI at admission above normal levels, n (\%) & $1(50)$ & $28(11.6)$ & 0.10 \\
\hline TNI after $3 \mathrm{~h}$ [ng/mL] & $0.06 \pm 0.004$ & $0.13 \pm 0.78$ & 0.91 \\
\hline TNI after 3 h above normal levels, n (\%) & $2(100)$ & $50(21)$ & 0.007 \\
\hline TNI after $3 \mathrm{~h}$ higher than at admission, n (\%) & $2(100)$ & $52(22)$ & 0.008 \\
\hline Hemoglobin $[\mathrm{g} / \mathrm{dL}](\mathrm{n}=243)$ & $10.8 \pm 1.2$ & $13.7 \pm 1.9$ & 0.02 \\
\hline Sodium [mEq/L] & $128.5 \pm 17.6$ & $138.7 \pm 3.7$ & 0.001 \\
\hline Potassium [mEq/L] & $4.6 \pm 0.2$ & $3.9 \pm 0.6$ & 0.13 \\
\hline Glucose $[\mathrm{mg} \%](\mathrm{n}=229)$ & $222 \pm 128$ & $123 \pm 42$ & 0.002 \\
\hline Creatinine [mg\%] & $1.12 \pm 0.28$ & $1.00 \pm 0.56$ & 0.48 \\
\hline D-dimer $[\mu \mathrm{g} / \mathrm{mL}](\mathrm{n}=215)$ & $1.25 \pm 1.01$ & $0.75 \pm 0.98$ & 0.48 \\
\hline D-dimer above normal levels, $n(\%)(n=215)$ & $1(50)$ & $63(30)$ & 0.53 \\
\hline CRP [mg\%] $(n=226)$ & $2.7 \pm 2.0$ & $7.8 \pm 16.2$ & 0.65 \\
\hline Magnesium [mg\%] $(\mathrm{n}=188)$ & $1.5 \pm 0.1$ & $2.0 \pm 0.3$ & 0.02 \\
\hline ECG results normal, n (\%) & $1(50)$ & $63(30)$ & 0.53 \\
\hline Hospitalization, n (\%) & $1(50)$ & $56(23)$ & 0.37 \\
\hline
\end{tabular}

* In cases where no results for a specific patient were available, the $\mathrm{n}$ value for persons whose results were available was used. HR - heart rate; TNI - troponin I; CRP - C-reactive protein; ECG - electrocardiography.

The ROC curve analysis revealed that among the biochemical parameters, only D-dimer level, and potassium and hemoglobin concentrations had significant cut-off points which could differentiate survivors and

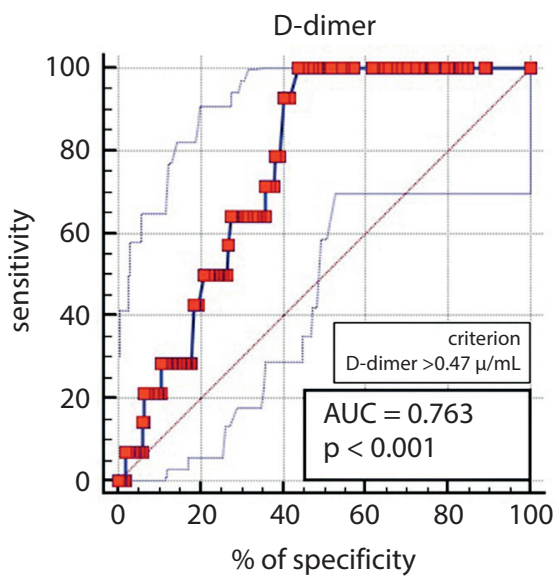

Fig. 2. Receiver operating characteristic (ROC) curve. D-dimer level for prediction of 1-year survival

AUC - area under curve. non-survivors (Fig. 2-4). The cut-off point for age was 75 years $(\mathrm{p}<0.001, \mathrm{AUC}=0.77)$. There was no significant cut-off point for TNI either at admission (Fig. 5) or after $3 \mathrm{~h}$.

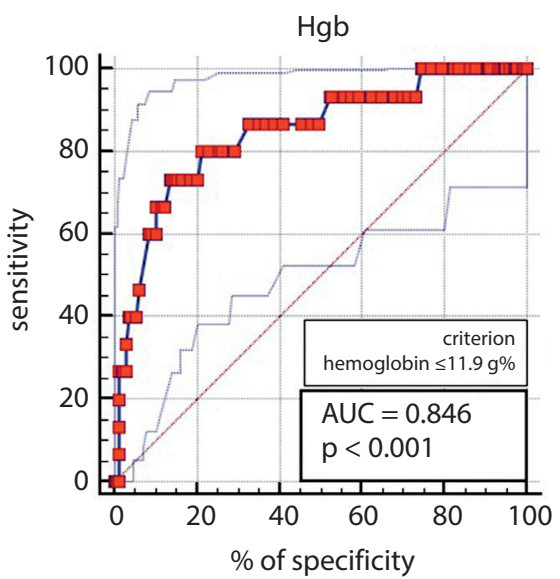

Fig. 3. Receiver operating characteristic (ROC) curve. Hemoglobin concentration for prediction of 1-year survival

AUC - area under curve. 
Table 3. Comparison of clinical and biochemical parameters of patients who survived 365 days as well as patients who died during this timeframe

\begin{tabular}{|c|c|c|c|}
\hline Characteristics* & $\begin{array}{l}\text { Patients who died within } 365 \text { days } \\
\qquad(\mathrm{n}=16)\end{array}$ & $\begin{array}{l}\text { Patients who survived } 365+\text { days } \\
\qquad(\mathrm{n}=227)\end{array}$ & $\mathrm{p}$-value \\
\hline Male gender, n (\%) & $5(31)$ & $9(44)$ & 0.34 \\
\hline Hypertension, n (\%) & $9(56.3)$ & $140(61.7)$ & 0.67 \\
\hline Diabetes, n (\%) & $8(50)$ & $33(15)$ & $<0.001$ \\
\hline Past stroke, n (\%) & $2(12.5)$ & $18(7.9)$ & 0.52 \\
\hline Systolic blood pressure [mm Hg] & $140.1 \pm 18.4$ & $136.8 \pm 20.8$ & 0.54 \\
\hline $\mathrm{HR}[\mathrm{bpm}]$ & $81.4 \pm 14.3$ & $77.9 \pm 14.7$ & 0.35 \\
\hline TNI at admission [ng/mL] & $0.41 \pm 1.6$ & $0.04 \pm 0.34$ & 0.006 \\
\hline TNI at admission above normal levels, n (\%) & $15(51.7)$ & $26(12.2)$ & $<0.001$ \\
\hline TNI after 3 h above normal levels, n (\%) & $7(43.8)$ & $45(19.8)$ & 0.024 \\
\hline TNI after $3 \mathrm{~h}$ higher than at admission, n (\%) & $8(50)$ & $46(20)$ & 0.006 \\
\hline Hemoglobin $[\mathrm{g} / \mathrm{dL}]$ & $11.3 \pm 1.9$ & $13.8 \pm 1.8$ & $<0.001$ \\
\hline Sodium $[\mathrm{mEq} / \mathrm{L}]$ & $135.7 \pm 7.1$ & $138.8 \pm 3.6$ & 0.003 \\
\hline Potassium [mEq/L] & $4.4 \pm 0.5$ & $3.9 \pm 0.6$ & 0.003 \\
\hline Glucose [mg\%] $(n=229)$ & $132.7 \pm 70.9$ & $129.9 \pm 40.8$ & 0.81 \\
\hline Creatinine [mg\%] & $1.16 \pm 0.26$ & $0.99 \pm 0.58$ & 0.25 \\
\hline D-dimer $[\mu \mathrm{g} / \mathrm{mL}](\mathrm{n}=215)$ & $1.2 \pm 1.0$ & $0.7 \pm 1.0$ & 0.07 \\
\hline D-dimer above normal levels, $n(\%)(n=215)$ & $9(64)$ & $55(27)$ & 0.003 \\
\hline CRP $[\mathrm{mg} \%](\mathrm{n}=226)$ & $12.2 \pm 14.2$ & $7.5 \pm 16.3$ & 0.27 \\
\hline Magnesium [mg\%] ( $n=188)$ & $2.0 \pm 0.5$ & $2.0 \pm 0.3$ & 0.63 \\
\hline Hospitalization, n (\%) & $8(50.0)$ & $59(21.6)$ & 0.009 \\
\hline
\end{tabular}

* In cases where no results for a specific patient were available, the $n$ value for persons whose results were available was used. HR - heart rate; TNI - troponin I; CRP - C-reactive protein; ECG - electrocardiography.

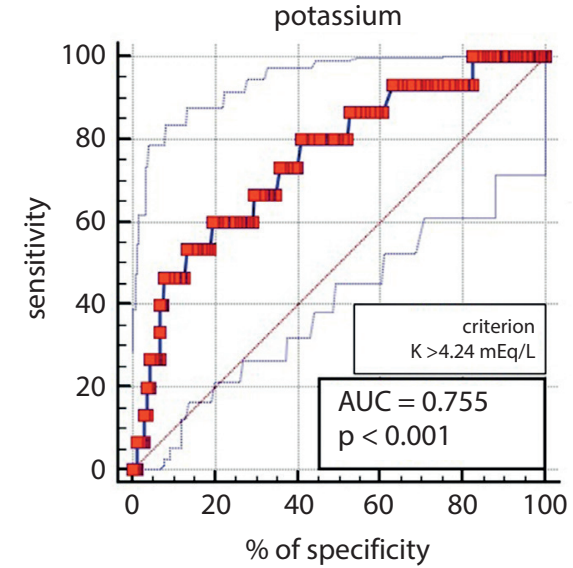

Fig. 4. Receiver operating characteristic (ROC) curve. Potassium level for prediction of 1-year survival

AUC - area under curve.

\section{Multivariable analysis}

The stepwise multivariable logistic regression analysis revealed that 1 -year mortality was related to an increased

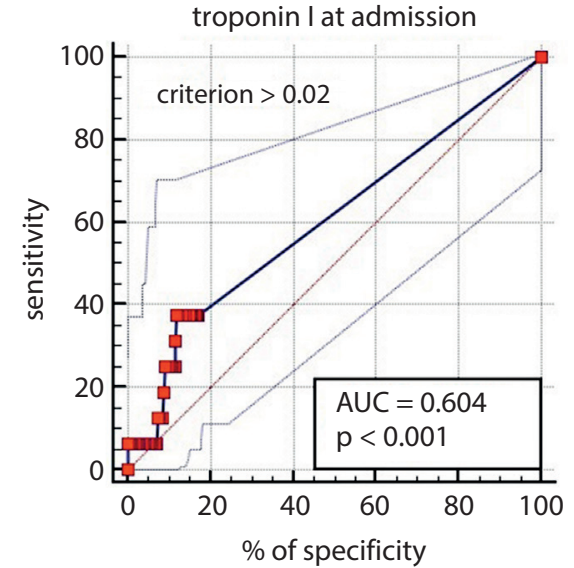

Fig. 5. Receiver operating characteristic (ROC) curve. Troponin I level for prediction of 1-year survival

AUC - area under curve.

level of $\mathrm{D}$-dimer $(\mathrm{OR}=8.5,95 \% \mathrm{CI}=21.9-37.5, \mathrm{p}<0.005)$, age $(\mathrm{OR}$ (per year) $=1.10,95 \% \mathrm{CI}=1.03-1.18, \mathrm{p}<0.03)$ and lower than $12 \mathrm{~g} \%$ hemoglobin concentration $(\mathrm{OR}=18.5$, $95 \% \mathrm{CI}=4.2-80.4, \mathrm{p}<0.001)$. 


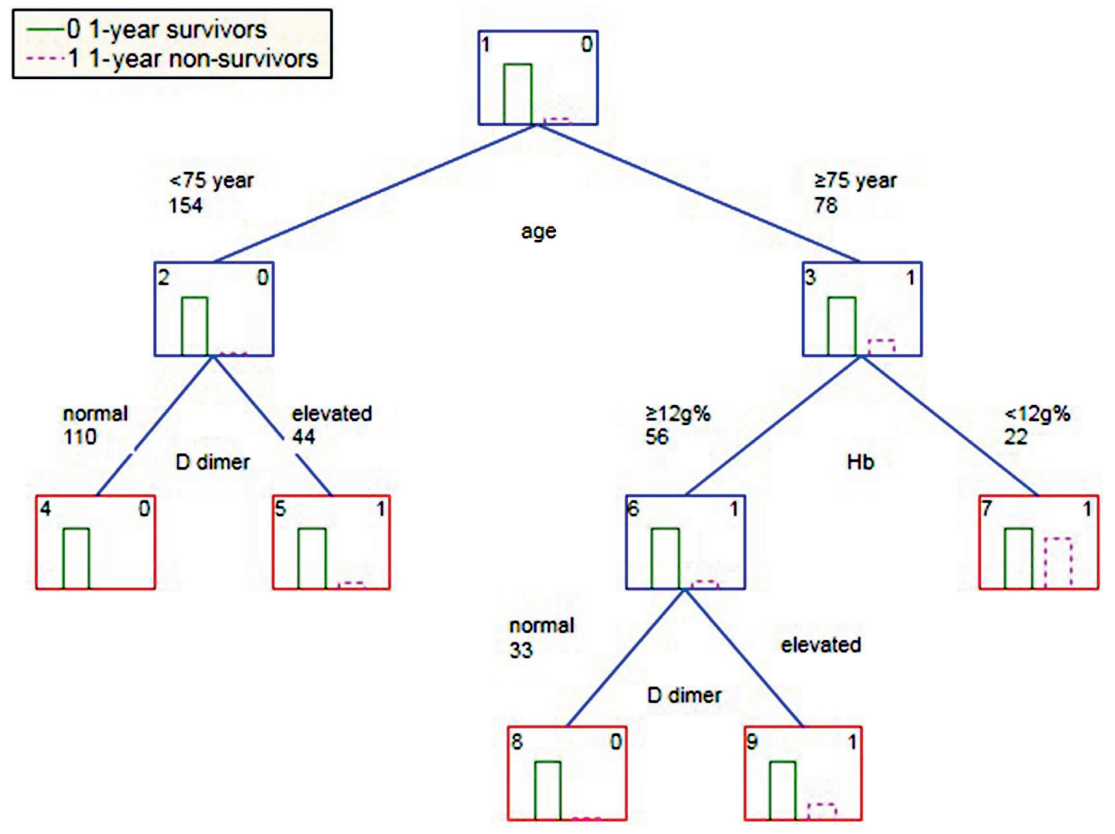

Fig. 6. Factors related to 1-year survival. Global cost $=0.23$; standard deviation $(S D)=0.06$. Model with demographic and clinical data

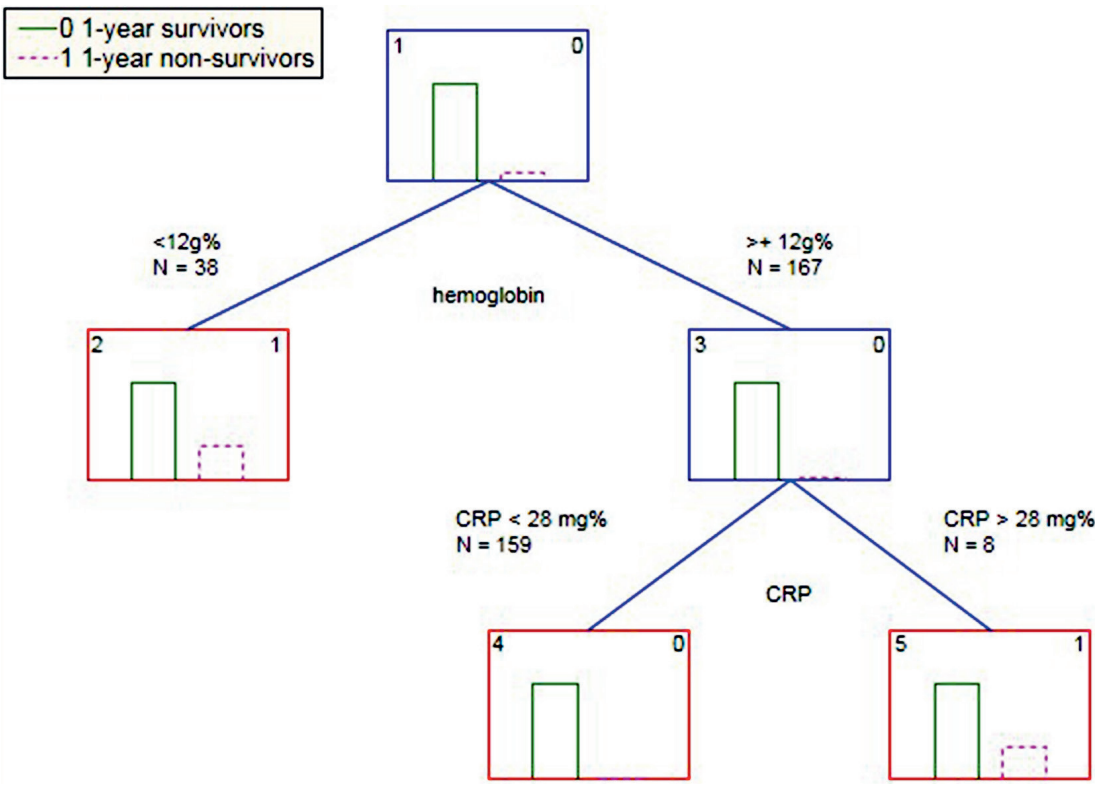

Fig. 7. Factors related to 1-year survival. Global cost $=0.20$; standard deviation $(S D)=0.05$. Model with clinical data, age not included in the analysis
In the model without age, the stepwise logistic regression analysis revealed that 1-year mortality was related to an increased level of D-dimer, lower than $12 \mathrm{~g} / \mathrm{dL}$ hemoglobin concentration and the presence of diabetes. Hospitalization, which was correlated to age (R-Spearman's coefficient $=0.25 \mathrm{p}<0.01$ ), was not a predictor of survival in either model.

The result of the nonlinear analysis carried out with the use of the CART method confirmed this result and revealed that a patient's death within 1 year was related with lower hemoglobin level, older age and increased D-dimer level (Fig. 6). After excluding age, the factors related to death were anemia and higher CRP level (Fig. 7). Troponin I levels and hospitalization were not related independently to mortality when other clinical factors were considered.

\section{Discussion}

The study group included patients reporting to the ED due to chest pain in whom no cardiovascular emergencies were found after initial diagnostic testing or during hospitalization in other departments. The studied patients formed a heterogeneous group regarding TNI concentration and D-dimer levels as well as age and present comorbidities.

The main finding of the study was that the survival of patients in the study group did not depend on hospitalization and in multivariate analysis it was found that factors other than TNI are related to poor prognosis. These factors were age, low hemoglobin level, increased D-dimer level, and increased CRP level. Increased troponin level 
is not itself a poor prognostic factor - it becomes one when there is a serious cardiovascular disease which presents with increased troponin level, like ACS, decompensated CHF or PE. The introduction of high-sensitivity cardiac troponin assays is associated with increased sensitivity and lower specificity. It has been demonstrated that in the population of patients with chest pain in whom no cardiovascular emergencies were found, higher troponin levels depended on the male sex, older age and impaired renal function. ${ }^{15}$

Other factors which may cause troponin increase are cardiac arrhythmias, CHF, hyperthyroidism, and chronic renal failure. Hospitalization may have little influence on the course of these diseases. Moreover, their impact on 1-year survival may be too low to be related with worse 1-year prognosis. Finally, other comorbidities, not defined at discharge, presenting with anemia or elevated CRP and D-dimer, may lead to increased 1-year mortality.

We presume that hospitalization had no influence on survival because these patients had no interventions which could have impact on long-term survival like coronary revascularization, cardioverter-defibrillator implantation, or treatment of acute heart failure or PE.

In published studies, a correlation between stable increased levels of troponin and mortality rate were proven even when ACS was not diagnosed. However, the groups assessed in those studies were much more homogeneous and comprised of a greater number of patients. Most often they were patients without a significant prior medical history. ${ }^{9-13}$ The authors know that chronic stable increased troponin concentration may result from a chronic heart injury and be associated with a worse prognosis as well as, for instance, with decreased renal function which constitutes a factor for atherosclerosis and death per se. One publication even showed a correlation between observable troponin concentration in a highly sensitive test of 5-9 $\mathrm{ng} / \mathrm{L}$, remaining below the $99^{\text {th }}$ percentile, and a greater 3-5-year risk of death due to cardiovascular as well as non-cardiovascular causes. ${ }^{13}$ In that study, similarly to our study, the studied group was not so homogeneous in relation to comorbidities; however, it included a considerably greater number of patients. In our study, a higher troponin concentration was correlated with a higher mortality rate. This indicates a significantly worse prognosis in patients with chronic heart injury, e.g., in the course of CHF.

The 60-day mortality in our group was very low and only 2 patients, with a mean age of 86 years, died during that period. One of the patients was hospitalized and the other one was discharged home from the ED.

The duration of the observation of patients after hospital discharge varied from 30 days to 1 year. The longer the observational period, the higher probability of death due to causes other than the factor which was responsible for chest pain.
A significantly greater mortality rate in both 60-day and 1-year observation groups, despite the lack of cardiac emergencies subjecting a patient to immediate hospitalization, indicates the significance of clinical parameters not included in the strict diagnostic algorithms of the above diseases and highlights the importance of an individual diagnostic approach to every patient.

\section{Limitations}

The main limitation of the study is that we do not know whether the modification of the treatment during hospitalization had an impact on the prognosis. However, such modifications may also be performed in the patients discharged home from the ED.

\section{Conclusions}

Hospitalization of patients with chest pain who were not diagnosed with ACS, PE, significant coronary stenosis, or decompensated CHF is not related with better survival and they can be safely discharged home from ED.

Sixty-day mortality is very low and occurs in older patients with numerous comorbidities.

Patients who died within 1 year had significantly higher rates of increased TNI concentration at admission and after $3 \mathrm{~h}$ than patients who survived this period; however, there were no cut-off points to distinguish these 2 populations.

In multivariate analysis, survival of the 1 -year period depends on the patient's age, hemoglobin levels and D-dimer levels.

Our results indicate that the risk of death in patients admitted to the ED due to chest pain in whom the cause of the chest pain was not due to cardiovascular emergencies depends on the presence of old age and comorbidities.

\section{ORCID iDs}

Przemysław Skoczyński (D) https://orcid.org/0000-0002-4998-8879 Joanna Wizowska (D) https://orcid.org/0000-0001-8746-1341 Paweł Pochciał (D) https://orcid.org/0000-0001-6580-5705

Marcin Leśkiewicz (D) https://orcid.org/0000-0003-0167-1618

Dorota Zyśko (D) https://orcid.org/0000-0001-9190-0052

\section{References}

1. Thygesen K, Alpert JS, Jaffe AS, Simoons ML, Chaitman BR, White HD; Writing Group on the Joint ESC/ACCF/AHA/WHF Task Force for the Universal Definition of Myocardial Infarction; ESC Committee for Practice Guidelines (CPG). Third universal definition of myocardial infarction. Eur Heart J. 2012;33(20):2551-2567.

2. Task Force for the Management of Acute Coronary Syndromes in Patients Presenting Without Persistent ST-Segment Elevation of the European Society of Cardiology (ESC). EUR Heart J. 2016;37(3):267-315.

3. The Task Force for the Management of Acute Myocardial Infarction in Patients Presenting with ST-Segment Elevation of the European Society of Cardiology (ESC). 2017 ESC Guidelines for the management of acute myocardial infarction in patients presenting with ST-segment elevation. Eur Heart J. 2017;38:1-66. 
4. Konstantinides SV, Torbicki A, Agnelli G, et al; The Task Force for the Diagnosis and Management of Acute Pulmonary Embolism of the European Society of Cardiology (ESC). 2014 ESC Guidelines on the diagnosis and management of acute pulmonary embolism. Eur Heart J. 2014;35(43):3033-3069.

5. Erbel R, Aboyans V, Boileau C, et al; ESC Committee for Practice Guidelines. 2014 ESC Guidelines on the diagnosis and treatment of aortic diseases. The Task Force for the Diagnosis and Treatment of Aortic Diseases of the European Society of Cardiology (ESC). Eur Heart J. 2014;35(43):2873-2926.

6. Savonitto S, Ardissino D, Granger CB, et al. Prognostic value of the admission electrocardiogram in acute coronary syndromes. JAMA. 1999;281(8):707-713.

7. Mandelzweig L, Battler A, Boyko V, et al; Euro Heart Survey Investigators. The second Euro Heart Survey on Acute Coronary Syndromes: Characteristics, treatment, and outcome of patients with ACS in Europe and the Mediterranean basin in 2004. Eur Heart J. 2006;27(19):2285-2293.

8. Terkelsen CJ, Lassen JF, Norgaard BL, et al. Mortality rates in patients with ST-elevation vs non-ST-elevation acute myocardial infarction: Observations from an unselected cohort. Eur Heart J. 2005;26(1): $18-26$.
9. Hammarsten O, Fu ML, Sigurjonsdottir R, et al. Troponin T percentiles from a random population sample, emergency room patients and patients with myocardial infarction. Clin Chem. 2012;58(3):628-637.

10. Roos A, Hellgren A, Rafatnia F, et al. Investigations, findings, and follow-up in patients with chest pain and elevated high-sensitivity cardiac troponin T levels but no myocardial infarction. Int J Cardiol. 2017;232:111-116.

11. Ahmed AN, Blonde K, Hackam D, lansavichene A, Mrkobrada M. Prognostic significance of elevated troponin in non-cardiac hospitalized patients: A systematic review and meta-analysis. Ann Med. 2014;46(8): 653-663.

12. Chapman AR, Adamson PD, Mills NL. Assessment and classification of patients with myocardial injury and infarction in clinical practice. Heart. 2017;103(1):10-18.

13. Roos A, Bandstein N, Lundbäck M, Hammarsten O, Ljung R, Holzmann MJ. Stable high-sensitivity cardiac troponin T levels and outcomes in patients with chest pain. J Am Coll Cardiol. 2017;70(18): 2226-2236.

14. Kozłowski D. Method in the chaos: A step-by-step approach to ECG interpretation. EJTCM. 2018;1:74-87.

15. Holzmann MJ. Clinical implications of high-sensitivity cardiac troponins. J Intern Med. 2018;284(1):50-60. 